Volume 8. No. 7, July 2020

International Journal of Emerging Trends in Engineering Research

Available Online at http://www.warse.org/IJETER/static/pdf/file/ijeter97872020.pdf

https://doi.org/10.30534/ijeter/2020/97872020

\title{
The Development of an Intelligent Complex of Radiation-Technological Control of a Safety Barrier
}

\author{
Serhii Lienkov ${ }^{1}$, Oksana Banzak ${ }^{2}$, Yuriy Husak ${ }^{3}$, Ihor Muliar ${ }^{4}$, Viktor Cheshun ${ }^{5}$, Evgeny Lenkov ${ }^{6}$ \\ ${ }^{1}$ Research Center, Military Institute of Taras Shevchenko National University of Kyiv, \\ Kyiv, Ukraine, lenkov_s@ukr.net \\ ${ }^{2}$ Department Electronics and Microsystem Technology of Odesa State Academy of Technical Regulation and \\ Quality, Odesa, Ukraine, banzakoksana@gmail.com \\ ${ }^{3}$ Research Center, Institute of the Armed Forces of Ukraine of Kyiv, Kyiv, Ukraine, y.husak1512@ gmail.com \\ ${ }^{4}$ Cybersecurity of Computer Systems and Networks of Khmelnytsky National University, \\ Khmelnitsky, Ukraine,iga2000@yahoo.com \\ ${ }^{5}$ Cybersecurity of Computer Systems and Networks of Khmelnytsky National University, \\ Khmelnitsky, Ukraine, dg2303@ukr.net \\ ${ }^{6}$ Scientific Center of the Military Institute of Telecommunications and Informatization, \\ Kyiv, Ukraine, torwer007@gmail.com
}

\begin{abstract}
The state of radiation-technological control of the safety barrier at nuclear power plants was analyzed in the article. The necessity for the further improvement of gamma radiation detection systems with the provision of higher metrological and operational indicators, as well as the use of new information processing algorithms is shown. There is an offer of the constructive usage of a sensor design based on a cadmium-mercury-tellurium compound and which is located on the body of a refueling machine for spent nuclear fuel. The results of determination of the gamma radiation spectra of two samples with excerpts of 11 months and 8 years are presented.
\end{abstract}

Key words: radiation technology control, safety barrier, gamma radiation spectrum.

\section{INTRODUCTION}

The human development requires more and more energy. Today, one of its main and practically inexhaustible sources is the energy of nuclear power plants (NPPs). In total, there are 451 nuclear reactors at 191 nuclear power plants in the world. Moreover, the total capacity in the countries is $1000 \mathrm{MW}$ : the USA - 100, France - 63, Japan - 39, China - 35, Russia - 26, South Korea - 23, Ukraine - 13. In many countries of the world (France - 72\%, Ukraine - 55\%, Slovakia, Belgium, Hungary) the nuclear energy makes up the major part of energy. NPPs less pollute the environment than thermal power stations, do not have an irreparable impact on the climate, and have a number of advantages. At the same time, there is a threat of accidents, including catastrophic ones, such as Chernobyl and Fukushima. This requires continuous improvement of protection methods, control and diagnostics of a number of parameters and situations. The level of development and use of radiation technology makes us quickly improve nuclear instrumentation. In a short period of time, this scientific field has gone through a development path upon monitoring the parameters of ionizing radiation from gas-discharge counters to scintillators, and then to semiconductor sensors, which have already been developed for more than a dozen generations. It should be noted that the basis for the progress of nuclear instrumentation is the simultaneous development of nuclear physics research and electronics.

The development of an intelligent complex of radiation-technological control of the state of physical safety barriers at the nuclear power plants is an important and urgent task. Obviously, we need new detection units with higher metrological and operational indicators, as well as new algorithms for processing the measured information to implement the new principles of radiation-technological control [1,2]. A significant breakthrough in improving the metrological and operational characteristics of detectors can be obtained only through the use of new materials, in particular, wide-gap semiconductors, such as CdZnTe $[1,3]$.

\section{METHODOLOGY}

We chose the measurement of the spectra of our own gamma radiation from nuclear fuel waste and other technological environments as the basic principle of construction of an intelligent complex of radiation-technological control of physical safety barriers. This choice is due to the significantly higher information content of gamma radiation measurements. For example, a methodology based on measurements of the spectra of intrinsic gamma radiation of a spent fuel assembly (SFA) allows to determine the burnout, exposure time, and initial enrichment of a controlled fuel assembly without using additional information. The data obtained by measuring the total neutron count rate do not 
allow estimating the burnout of nuclear fuel waste without using additional information about the exposure time and initial enrichment [4]. Since the introduction of new intelligent complexes of radiation-technological control should not lead to a decrease in the efficiency of operation of the unit, the operations of monitoring the status of protective barriers should be coordinated by the technology of electricity production and equipment repair, with a time schedule for the process of reloading nuclear waste. Therefore, the main criterion in constructing the structure of the intellectual complex of radiation-technological control should be its performance in real time. During the execution of the technological operation, the time characteristic of changing a parameter during operation at the power of an intelligent complex of radiation-technological control should ensure the measurement of the own gamma radiation of a spent fuel assembly and other technological environments, conduct an amplitude analysis of the counting pulses, process the spectrum of its own gamma-radiation, calculate the characteristics of the state of the protective barrier and enter them into the database. The work of the intellectual complex of radiation-technological control in this mode will be hereinafter referred to as a real-time operation, while the following basic principle of constructing real-time systems is observed: the rate of data input into the system (characteristics of the own gamma radiation of the fuel assembly, coolant and primary circuit equipment, gas in the pressurized shell) should correspond to the rate of formation of the system output data (characteristics of the state of spent nuclear fuel). The basic requirements for an intelligent complex of radiation-technological control in real time based on the formulated real-time criterion can be divided into the following groups $[4,5]$ :

1. Measurement quality. Measurements should ensure that such a volume of information is obtained that the additional time required to determine all monitored parameters would be minimal.

2. Mass and size requirements. The mechanical design of the main elements of the system should ensure good compatibility with existing technological equipment and controls of the refueling machine to ensure to ensure compliance with safety requirements during the reloading of nuclear fuel, and not introduce restrictions on the maintenance of nuclear waste.

3. Operating conditions. The design of the basic elements of the intellectual complex of the radiation-technological control of the system should ensure that radiation measurements are taken under the actual operating conditions of the power unit of the nuclear power plant. At the same time, a differentiated approach should be provided, in which the real operating conditions of each element of the system are taken into account.

4. Reliability. Since the incorrect functioning of the system (false operation of the system, or failure to detect the violation of the protective barriers) can lead to significant economic losses (reduced power, additional time spent on equipment repair, etc.), the loss of time due to the inoperability of the system should be minimal. The reliability of the system must be consistent with the reliability of system equipment important to safety.

5. Convenience of service and operation. This group of requirements is directly related to ensuring the reliability of the system and the effectiveness of the system at all stages of its life cycle.

In addition, based on the above requirements, it can be concluded that it seems most appropriate to place the detectors on the working rod of the reloading machine from the point of view of combining technological operations for monitoring the state of nuclear fuel waste and its overload [5]. At the same time, the detectors are placed in a specially designed construction installed on the outer section of the working rod of the reloading machine, which is schematically shown in Figure 1.

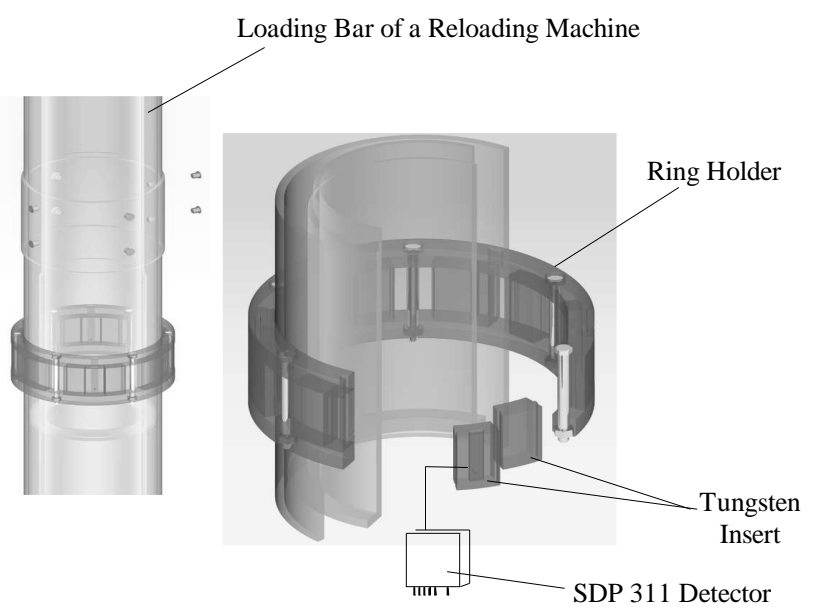

Figure 1: Placement of detectors on the working rod of the reloading machine

The construction installed on the working rod allows combining the protection and collimator functions and consists of the following components:

1. The lower base of stainless steel with a thickness of 25-30 $\mathrm{mm}$ with a profiled neckline.

2. Segmented tungsten plates with installed (mounted) semiconductor $\mathrm{CdZnTe}$ detectors and sealed connectors.

3. The upper base of stainless steel with a thickness of $15-20 \mathrm{~mm}$ with a profiled neckline.

4. Banding joints (stainless steel bolts $350-400 \mathrm{~mm}$ long). The proposed construction also provides unambiguous and clearly reproducible positioning of the detectors concerning the controlled fuel assembly for the all gamma-radiation recording series. The construction allows you to place multiple detectors at a distance of $22.5 \mathrm{~cm}$ from the axis of the controlled fuel assembly.

\section{RESULT AND DISCUSSION}

The detector is a determining element in the construction of the system as a whole, since it determines the fulfillment of such requirements as the quality of measurements, weight and size parameters. The main measuring parameters of the 
detector, under which they applicability in various systems of analysis and control, are energy resolution, recording efficiency, and the hardware spectrum as a whole.

One very important feature of all CdZnTe detectors due to the difference in the mobility of charge carriers is the pulse shape, namely, a short front. The pulse front at the output of the $\mathrm{CdZnTe}$ detector is much shorter than the pulse front of the germanium-based semiconductor detector, and even more so than the pulse front at the output of the scintillation detector [3].

This feature predetermines the special requirements for a multi-channel amplitude analyzer both at the level of analog input circuits built into the analyzer and at the performance level of an analog-to-digital converter.

The requirement for the highest reliability of the sensorsystem of data processing and data storing processing the solution of which was proposed by the authors $[6,7]$ has a particular importance. For use of the control system for burning nuclear waste, it is necessary to use a multichannel amplitude analyzer, in which the work with CdZnTe detectors is provided by the manufacturer, as well as the work with a time constant generating input circuits of $1 \mu \mathrm{s}$ or $0.5 \mu \mathrm{s} \mathrm{I}$ implemented, the natural frequency of an analog-to-digital converter should be not less than $80 \mathrm{MHz}$. At present, the multichannel amplitude analyzers which support the operation of $\mathrm{CdZnTe}$ detectors are already mass-produced. At the same time, most of the analyzers are manufactured in wearable design, making maximum use of the capabilities of $\mathrm{CdZnTe}$ detectors for field measurements. Since most of these analyzers have been developed in recent years, they have implemented the most advanced circuitry solutions and they are significantly superior to analyzers constructed according to the traditional scheme. Among wearable analyzers, MCA-166 manufactured by GBS (Germany) is most widely used. It is ideally suited for controlling gamma radiation, for example remotely with the help of geocopters [8, 9]. However, the use of such analyzers in a wearable design to create an industrial design of the system is not optimal, since in this case the operational requirements and the requirements for ease of maintenance and operation are poorly fulfilled; the reliability of the design is reduced during multi-detector measurements.

The system of $n$ detectors forming the detection unit should register its own gamma radiation from nuclear fuel waste during the extraction of the fuel cartridge and convert it into electrical signals for subsequent transmission to the amplitude analyzer.

The multichannel amplitude analyzer should carry out the functions of accumulation, processing, and subsequent computer transmission of the information on the distribution of count pulses from detectors by amplitudes, i.e. primary (untreated) gamma spectrum. Futher, it is necessary to search for the absorption peaks in the obtained spectra, determine the peak area, determine the radiation intensity at the total absorption peak, and actually calculate the burnout of nuclear fuel waste of the controlled fuel assembly and maintain a database. These functions are assigned to the computer of the burnout depth determination system [10]. In accordance with the formulated requirements for the system, the following structural diagram is made (Figure 2.)

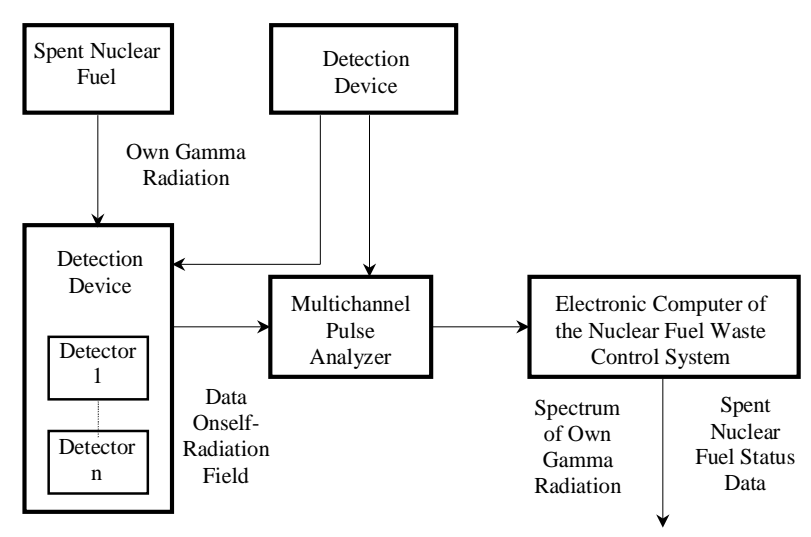

Figure 2: Structural diagram of a system for monitoring the status of spent nuclear fuel in real time

The main measuring parameters of the detector, which assess their applicability in various systems of analysis and control, are energy resolution, recording efficiency, and the hardware spectrum as a whole. The energy resolution of the detector should be no less than $9 \mathrm{keV}$ registering gamma radiation with an energy of $661.6 \mathrm{keV}$, and with an input load of $15,000 \mathrm{pulses} / \mathrm{s}$. The detector must ensure the conservation of spectrometric properties at an input load of up to 200,000 pulses/s, while the energy resolution of the detector should be no less than $30 \mathrm{keV}$.

Based on the SDP310/LC/20S detectors, a prototype of a real-time nuclear fuel waste burnout control system was created and tested at the Zaporizhzhya NPP. Typical gamma spectra (two of them in Fig. 3, 4) obtained at different values of burnout, enrichment and exposure time are shown in Figures 3 and 4 .

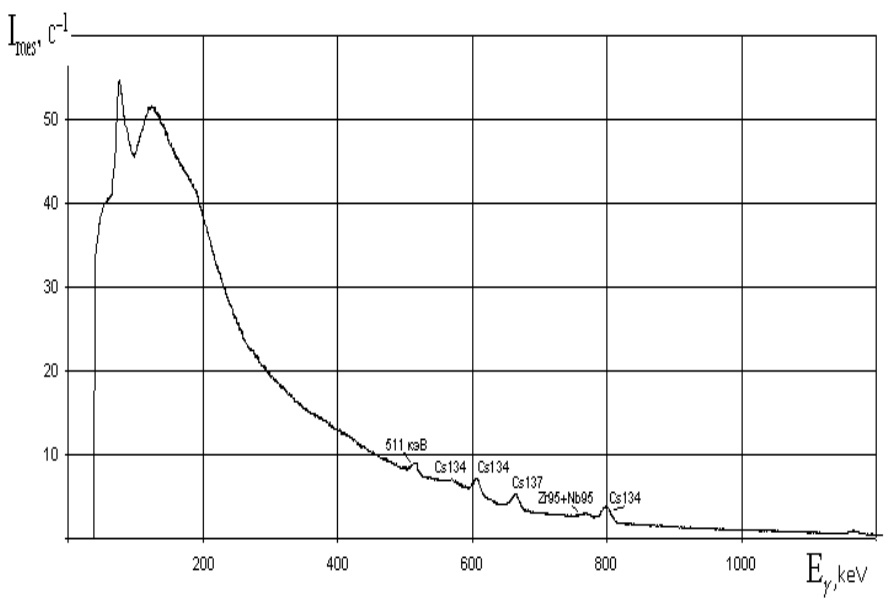

Figure 3: The radiation spectrum of the SFA E 2957 with a burnout of $37.23 \mathrm{MW} \cdot$ day $/ \mathrm{kg}$ and exposure for 11 months 


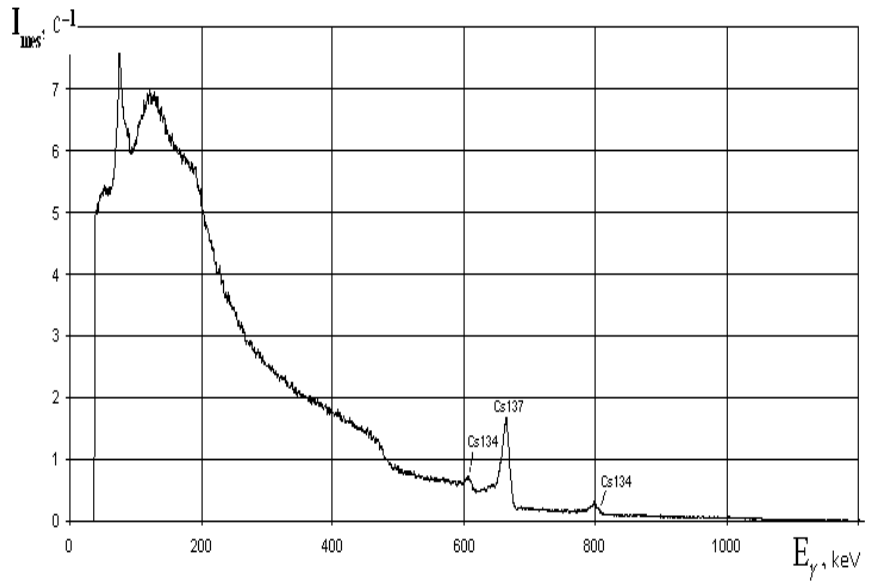

Figure 4: The radiation spectrum of the SFA GV 2278 with a burnout of $30.58 \mathrm{MW} \cdot$ day $/ \mathrm{kg}$ and exposure for 8 years

Thus, experimental studies have confirmed that the choice of a monitoring system and detectors such as SDP310/LC/20S (SDP311/LC/20S) of Ritec Company is a successful one. From the point of view of choosing the number of detectors necessary to solve a specific technical and economic problem related to burnout control, it is interesting to answer the question of which part (zone) of the fuel assembly is controlled by one detector. To achieve this goal, the coefficients of the contributions of individual thermal elements to the intensity were quantitatively analyzed at the detector. The analysis was performed for the angles corresponding to the midpoints of the faces of the fuel assembly and its edges for various isotopes.

\section{CONCLUSION}

One of the main directions of ensuring the safety of nuclear power plants by creating an intelligent complex of radiation-technological control of the safety barrier was shown in the article. It is advisable to carry out the main burnout control of the spent fuel assembly when reloading nuclear waste.

The most effective gamma radiation sensors today are wide-gap semiconductors based on cadmium-zinc-tellurium compounds. The basic requirements of the complex of radiation-technological safety control of the barrier are considered. Its design concept was suggested. The experimental measurements of the gamma-ray spectra of spent fuel assemblies have been carried out and have shown the high efficiency of the proposed monitoring system.

\section{REFERENCES}

1. Ya. I. Lepikh, Yu. O. Gordienko, S. V. Dzyadevich, A. O. Druzhinin, A. A Yevtukh, S. V. Lenkov, V. G. Melnik, B. O. Protsenko, V. O. Romanov. Intelligent measuring systems based on new generation microelectronic sensors, monograph, Odessa, 352 p., 2011.

2. O. V. Bansak. Development of a software and hardware complex for radiation-technological control of steam generator leaks based on Cd-Zn-Te-detectors, Collection of Scientific Works of the Military Institute of Kyiv National Taras Shevchenko University, Kyiv, № 49, pp. 90 - 95, 2015.

3. O. V. Bansak, A. V. Karpenko S. V. Lenkov, O. V. Maslov. Gamma radiation sensor based on cadmium-zinc tellurium (CZT), Modern special technology, № 2(29), pp. 27-32, 2012.

4. A. Tiitta, A. M. Dvoyeglazov, S. M. Iievlev, M. Tarvainen, M. Nikkinen. VVER-1000 SFAT specification of an industrial prototype, Helsinki, 41 p., 2000.

5. O. V. Maslov, S. G. Oleinik. Automated system for controlling the distribution of fission products in VVER-1000 fuel assemblies during nuclear fuel reloading, Second Russian Intern. Conf. "Accounting, control and physical protection of nuclear materials", Obninsk, pp. 3-88, 2000.

6. S. Lenkov, G. Zhyrov, D. Zaytsev, I. Tolok, E. Lenkov, T. Bondarenko, Y. Gunchenko, V. Zagrebnyuk, O. Antonenko. Features of modeling failuresofre coverable complex technical objects with a hierarchical constructive structure, Eastern European Journal of Advanced Technology, Kharkiv, №4/4(88), pp. 34-42, 2017,

DOI:10.15587/1729-4061.2017.108395.

7. G. Zhyrov, S. Lienkov, Y. Husak, H. Banzak, I. Tolok. Analysis of problem optimization of parameters maintenance process according to state with constant periodicity of control, International Journal of Emerging Trends in Engineering, vol. 8, No.6, 2020, available at

http://www.warse.org/IJETER/static/pdf/file/ijeter63862 020, DOI:10.30534/ijeter/2020/63862020.

8. S. Lienkov, A. Myasische, O. Banzak, Y. Husak, I. Starynski. Use of rescue mode for UAV on the basis of STM32 microcontrollers, International Journal of Advanced Trends in Computer Science and Engineering, vol. 9, No.3, available at: http://www.warse.org/IJATCSE/static/pdf/file/ijatcse15 6932020, DOI:10.30534/ijatcse/2020/15693202.

9. S. A. Shvorov, N. A. Pasichnyk, S. D. Kuznichenko, I. V. Tolok, S. V. Lienkov, L. A. Komarova. Using UAV during Planned Harvesting by Unmanned Combines, IEEE 5th International Conference Actual Problems of Unmanned Aerial Vehicles Developments, pp. 252-257, 2019. https://doi.org/10.1109/APUAVD47061.2019.8943842

10. V. A. Mokritsky, O. V. Maslov, O. V. Banzak. Method for determining the depth of combustion of spent nuclear fuel (SNF), Collection of scientific works of the Military Institute of Taras Shevchenko National University of Kyiv, Kyiv, №45, pp. 79 - 83, 2014. 